\title{
Snapper Pagrus auratus (Sparidae) home range dynamics: acoustic tagging studies in a marine reserve
}

\author{
D. M. Parsons ${ }^{1,5, *}$, R. C. Babcock ${ }^{1,6}$, R. K. S. Hankin ${ }^{2}$, T. J. Willis ${ }^{1,7}$, \\ J. P. Aitken ${ }^{3,8}$, R. K. O'Dor ${ }^{3,9}$, G. D. Jackson ${ }^{4}$ \\ ${ }^{1}$ Leigh Marine Laboratory, University of Auckland, PO Box 349, Warkworth, New Zealand \\ ${ }^{2}$ School of Geography and Environmental Science, University of Auckland, Private Bag 92019, Auckland 1020, New Zealand \\ ${ }^{3}$ Department of Biology, Dalhousie University, Halifax, Nova Scotia B3H 4R2, Canada \\ ${ }^{4}$ Institute of Antarctic and Southern Ocean Studies, University of Tasmania, GPO Box 252-77 Hobart, Tasmania 7001, Australia \\ Present addresses: ${ }^{5}$ Department of Marine, Earth and Atmospheric Sciences, North Carolina State University, Box 8208, \\ Raleigh, North Carolina 27695, USA \\ ${ }^{6}$ CSIRO Marine Research, Private Bag 5, Wembley, Western Australia 6913, Australia \\ ${ }^{7}$ Scienze Ambientali, Università di Bologna, Via Tombesi dall'Ova 55, 48100 Ravenna, Italy \\ ${ }^{8}$ Department of Zoology, Downing Street, University of Cambridge, Cambridge CB2 3EJ, UK \\ ${ }^{9}$ Census of Marine Life, 1755 Massachusetts Avenue, NW \#800, Washington, DC 20036, USA
}

\begin{abstract}
The home-range size and location of reef-associated snapper Pagrus auratus: Sparidae were investigated by use of a radio acoustic-positioning telemetry (RAPT) system. Tags were surgically implanted in 5 snapper that were subsequently monitored every minute for a period of 5 mo, and then intermittently over another 7 mo. Site fidelity was high amongst these fish, with home ranges not exceeding $650 \mathrm{~m}$ in diameter or $139600 \mathrm{~m}^{2}$ in area. Eleven other snapper received tags by feeding and were tracked for periods of up to $2.5 \mathrm{~d}$. Site fidelity was also high for these fish, with standardised estimates of home-range size not differing between the 2 groups. Home ranges overlapped considerably, indicating that the fish were not territorial. The location of the home ranges generally remained stable throughout the entire tracking period, although 1 fish relocated its home range by $\sim 220 \mathrm{~m}$. A new method of home-range estimation was developed, which matched the level of detail provided by the RAPT system, to directly estimate the time spent in an area. The relevance of this method and the residential behaviour of these fish are discussed, with reference to the general understanding of animal behaviour, previous investigations into snapper movement, and the selective capacity that may be imposed by marine reserves on fish behaviour.
\end{abstract}

KEY WORDS: Pagrus auratus · Snapper behaviour - Home range · Site fidelity · Residency · Utilisation distribution · New Zealand · Marine reserve

\section{INTRODUCTION}

The home-range parameters of animals interest biologists for 2 main reasons (Schoener 1981): (1) homerange size can be related to feeding strategy, food density, resource use, metabolic demands, behaviour and efficiency of movement; (2) home-range characteristics can reflect both inter- and intraspecific interactions. Home range parameters interest conservationists and fisheries managers through their direct application to species management. For example, an understanding of fish home-range or behaviour is crucial to the effectiveness of marine reserve design (Roberts \& Polunin 1991, Attwood \& Bennett 1994, Holland et al. 1996, 
Zeller 1997, Allison et al. 1998, Woodroffe \& Ginsberg 1998, Kramer \& Chapman 1999, Willis et al. 2000). Whether the reserve's goal is to increase fish abundance within the reserve (i.e. to protect brood stock) or to supplement the adjacent fishery through the emigration of fish or larval production from the reserve, both of these goals could be fulfilled by a spatial restriction on fishing. However, the size of the reserve relative to the mobility of the fish will influence the degree to which reserve population recovery is undermined by emigration to fished areas. Theoretically, a species with intermediate dispersal capabilities, relative to reserve size, should provide a balance between emigration to the fishery and accumulation of brood stock (DeMartini 1993). Species with higher mobility would not reside within the reserve long enough to receive significant protection, while highly resident species would recover the fastest but would have low emigration rates to fished areas.

In NE New Zealand, snapper Pagrus auratus (Sparidae) form the basis of the largest commercial and recreational fishery (Annala et al. 1999). Snapper are also the most abundant carnivorous fish within the inshore areas of northern New Zealand (Paul 1976), and are important at economic, cultural and ecological levels. For this reason marine reserve designs in NE New Zealand should optimise the effective protection of snapper. A well-designed reserve would maximise snapper biomass and therefore increase egg production (e.g. Willis et al. 2003), as well as have the potential to benefit the fishery through emigration of adults. If these goals are achieved, reserves may allow ecosystem 'recovery' by elevating snapper abundances to a level where exertion of top-down processes could regulate lower trophic levels, altering community structure and productivity to a state reflecting the absence of fishing (Babcock et al. 1999, Shears \& Babcock 2002).

Despite their local importance, current knowledge of home-range and space-use characteristics of snapper is lacking. There is evidence suggesting that both resident and mobile behaviours are exhibited by snapper. For example in Shark Bay, Western Australia, tagged snapper from within the gulfs of Shark Bay were not recaptured more than $42 \mathrm{~km}$ from where they were tagged, whereas snapper from the open coast were recaptured up to $322 \mathrm{~km}$ from the tagging site (Moran 1987). In New Zealand similar results have been gathered from tagging studies. The majority of recaptures have been within $20 \mathrm{~km}$ of the tagging location, but some snapper were recaptured up to $418 \mathrm{~km}$ from the site of tagging (Paul 1967, Crossland 1976, Gilbert \& McKenzie 1999).

Within the Cape Rodney to Okakari Point (CROP) Marine Reserve, the site of this study, the density of snapper above minimum legal size is 16 times greater than in adjacent fished areas (Willis et al. 2003). As the reserve only encompasses $5 \mathrm{~km}$ of coastline, the elevated densities alone suggest a degree of site fidelity. Berquist (1994) investigated this residency by acoustically tagging 2 snapper within the reserve. Both fish remained within an $800 \mathrm{~m}$ diameter for 2 and $5 \mathrm{~d}$, respectively. Using individually coded elastomer tags, Willis et al. (2001) marked 117 snapper within the CROP Reserve. Forty-nine of these fish were resighted repeatedly over several months, and the greatest distance between relocations was only $500 \mathrm{~m}$.

The aim of this study was to describe the movements of 'resident' snapper within the CROP Marine Reserve, using a radio-acoustic positioning and telemetry (RAPT) system to accurately track individuals over periods of a few months. The positional fixes provided by the RAPT system were often very frequent (every minute), but provided at irregular intervals. Due to this irregular sampling frequency, we present a new method of estimating home ranges where time is used as the contouring variable. Of further interest were (1) any changes in the home-range size and location over a period of months; and (2) differences between the home range parameters of snapper that were fed tags and those that had tags surgically implanted.

\section{MATERIALS AND METHODS}

Experimental area and procedure. This study was conducted in the CROP Marine Reserve primarily from January to June 2000, although further, less frequent observations were made through to January 2001. During this time snapper were continuously tracked via the use of a RAPT system (VEMCO). This system allowed accurate positioning ( \pm 1 to $2 \mathrm{~m}$ ) (O'Dor et al. 1998) of individual fish, with a temporal resolution of minutes. Each monitored snapper contained a transmitter (pinger) that broadcast on a frequency unique to that individual. The ultrasonic signal transmitted from each fish was then received by 3 moored sono-buoys that relayed data to a land-based computer by radio signal. The computer then triangulated the position of the fish based on differences in arrival time of the signals. The sono-buoys were placed in a triangular configuration, approximately $300 \mathrm{~m}$ apart, within Goat Island Bay (Fig. 1). This area was chosen for its high abundance of snapper, shelter and the presence of shallow reef-habitat.

This study used V16 and V8 transmitters, also made by VEMCO. Five snapper (Table 1) received surgically implanted V16 transmitters. These V16 transmitters, $\sim 16 \mathrm{~mm}$ diameter and $7.5 \mathrm{~cm}$ length, had a battery life conservatively estimated at $120 \mathrm{~d}$ (but were found to last much longer in water temperatures of 16 to $20^{\circ} \mathrm{C}$ ). 
This allowed long-term detailed monitoring of snapper movements. The V8 transmitters $(\sim 8 \mathrm{~mm}$ diameter and 45 $\mathrm{mm}$ length) were small enough for snapper to swallow in situ, encased in bait, without any handling of the fish. The transmitter would be retained for ca. $2 \mathrm{~d}$ before passing through the body, at which time the transmitter could be relocated and retrieved using a diveroperated receiver (VUR96, VEMCO). The transmitter could then be fed to another fish. A total of 11 snapper from ca. 250 to $450 \mathrm{~mm}$ fork length (FL) were monitored for ca. 2 d each, by use of V8 transmitters (Table 1).

Fish capture, handling and surgery. Snapper were caught from the CROP Reserve on hook and line, using modified barbless hooks (see Willis \& Millar

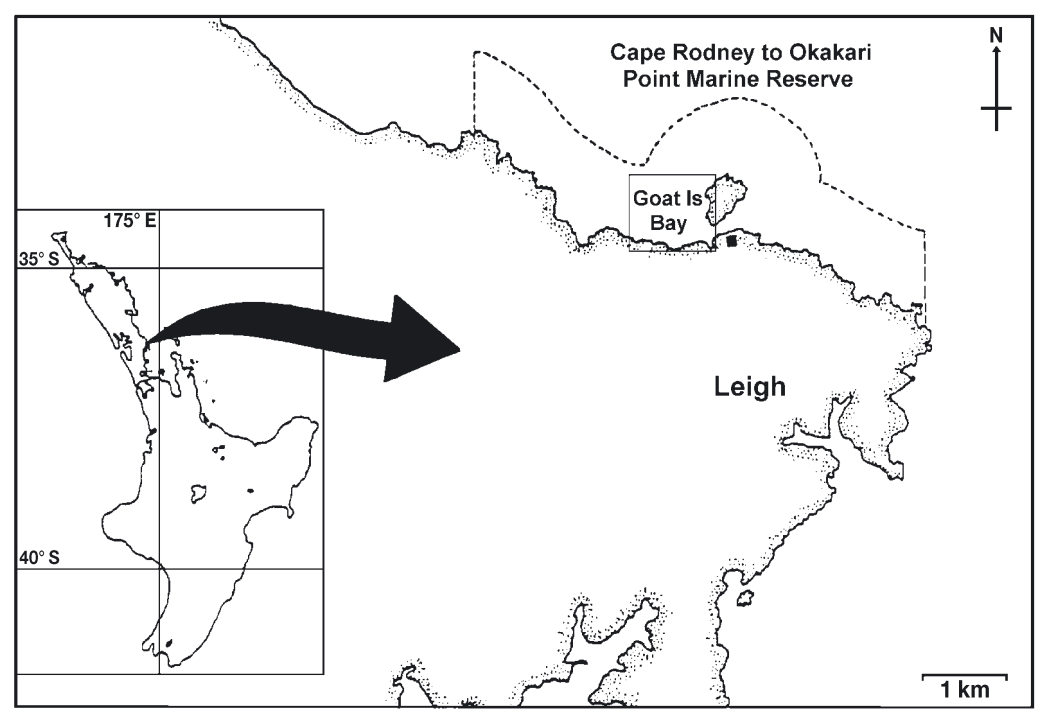

Fig. 1. Location map of North Island, New Zealand, and study area
2001) to reduce injury and the proba-

bility of 'gut hooking'. Surgical procedures followed the methods described by Zeller (1997). After capture, each fish was retained in an aquarium tank for $24 \mathrm{~h}$ to reduce stress levels before surgical insertion of ultrasonic transmitters. Fish were anaesthetised with clove oil at $0.27 \mathrm{ml} \mathrm{l}^{-1}$ (Munday \& Wilson 1997). After the fish had become immobile it was placed in a sponge cradle and the incision area was de-scaled and then sterilised with Tamodine (Vetark products). An incision approximately $2 \mathrm{~cm}$ long was made $1 \mathrm{~cm}$ from the mid-line of the fish and 2 to $3 \mathrm{~cm}$ anterior of the anus. The transmitter was then inserted into the gut cavity. The wound

Table 1. Pagrus auratus. Summary details of fish receiving V8 tags (via feeding; fish no. beginning with F) and V16 tags (implanted; fish no. beginning with S). FL: fork length

\begin{tabular}{|lccc|}
\hline Fish no. & $\begin{array}{c}\text { Fish size } \\
\text { (mm FL) }\end{array}$ & $\begin{array}{c}\text { Date released } \\
\text { (dd/mm/yy) }\end{array}$ & $\begin{array}{c}\text { Days } \\
\text { monitored }\end{array}$ \\
\hline F1 & 325 & $09 / 03 / 00$ & 2.3 \\
F2 & 400 & $15 / 03 / 00$ & 2.5 \\
F3 & 450 & $20 / 03 / 00$ & 1.0 \\
F4 & 400 & $20 / 03 / 00$ & 0.8 \\
F5 & 300 & $22 / 03 / 00$ & 1.2 \\
F6 & 300 & $24 / 03 / 00$ & 1.9 \\
F7 & 400 & $27 / 03 / 00$ & 0.3 \\
F8 & 375 & $28 / 03 / 00$ & 0.2 \\
F9 & 350 & $13 / 04 / 00$ & 1.6 \\
F10 & 400 & $16 / 05 / 00$ & 2.0 \\
F11 & 250 & $19 / 05 / 00$ & 0.8 \\
S4 & 426 & $24 / 01 / 00$ & 130 \\
S2 & 415 & $24 / 01 / 00$ & 141 \\
S3 & 532 & $24 / 01 / 00$ & 141 \\
S1 & 400 & $30 / 01 / 00$ & 141 \\
S5 & 515 & $04 / 02 / 00$ & 135 \\
\hline
\end{tabular}

was sealed with nylon sutures and each fish received an injection of tetracycline antibiotic $\left(50 \mathrm{mg} \mathrm{kg}^{-1}\right.$ of fish). During surgery the gills were irrigated with alternate doses of pure seawater and diluted anaesthetic to ensure the fish was ventilated but remained unconscious. Each fish was then left to recover for at least $24 \mathrm{~h}$ in an aquarium tank before release at the site of capture. No mortality occurred during this process.

After release, manual relocations of tagged fish were made using a hand-held directional hydrophone (VR60) and a diver-operated hand-held receiver (VUR96). These were also used to record additional fish locations after the RAPT system had been removed from Goat Island Bay. All snapper were also tagged with individually coded fluorescent elastomer tags implanted in the caudal fin membranes (Willis \& Babcock 1998) to allow in situ visual identification.

Data processing. Using the programming software Octave, Version 2.0 (Eaton \& Rawlings 1995), the locations of each fish were recalculated from the 'R-files' generated by the RAPT system. This procedure was required because the software provided by VEMCO only recorded the average of each series of positions ('D-files'). This meant that data would have been lost through an unquantified averaging process. After all raw positions had been calculated, the data were smoothed by the following set of criteria: (1) If a location was calculated more than $1000 \mathrm{~m}$ from the centre of the buoy array it was deleted. VEMCO specify that the RAPT system can detect pingers up to $1 \mathrm{~km}$ from the buoy array (O'Dor et al. 1998), however accuracy decreases rapidly beyond this distance. (2) While the tracking system was receiving data, certain files were noted to contain obviously erroneous buoy positions, due 
to spurious signals during rough weather ( $>20$ knots wind speed). Data received during these noted periods were also deleted. (3) Spurious points were removed by the following algorithm: Between each triplet of consecutive fixes, the 2 speeds (Point 1 to Point 2 and Point 2 to Point 3 ) were calculated. If the minimum of these 2 speeds exceeded a certain maximum swimming speed, the middle point was deleted; typically, Points 1 and 3 were within a metre or so of one another, and Point 2 was hundreds of metres away. This process was applied recursively until no 2 consecutive fixes were separated by a speed exceeding the maximum swimming speed. The precise value of the maximum swimming speed was not critical; using values between 1 and $10 \mathrm{~m} \mathrm{~s}^{-1}$, we applied this algorithm to positions obtained from an acoustic tag secured in a known location. This resulted in only slightly differing smoothed datasets. Because maximum swimming speeds for snapper (or indeed other sparids) are not known, a conservative value of $4 \mathrm{~m} \mathrm{~s}^{-1}$ was used. This value is consistent with the work of Blaxter \& Dickson (1959), who specified a maximum swimming speed of $\sim 2$ to $3 \mathrm{~m} \mathrm{~s}^{-1}$ for Atlantic mackerel Scomber scombrus. In addition, measurement of snapper swimming speeds observed here did not exceed $0.5 \mathrm{~m} \mathrm{~s}^{-1}$.

Home range estimation. To estimate home ranges from smoothed data, the tracking area was divided into a grid composed of $20 \times 20 \mathrm{~m}$ bins. The amount of time individual fish were detected in each of these bins was then calculated using software written in Matlab ${ }^{\mathrm{TM}}$ (MathWorks 1998). This required 2 assumptions to be made: (1) The fish swam in a straight line between consecutive positional fixes as long as these fixes were not more than 30 min apart. Although the RAPT system attempted to locate a fish every minute, if the fish's acoustic signal was obscured by sea-floor structures or wave-generated noise, a fix would not be achieved. Therefore, a time lapse of greater than 30 min between fixes could occur. (2) The speed at which the fish swam between these 2 points was constant and equal to the distance divided by the time elapsed between 2 consecutive positional fixes. This allowed the location of the fish to be estimated between fixes as long as the tracking system located the fish every $30 \mathrm{~min}$ or less. In this way, an estimate of the amount of time a fish spent within each bin of the tracking area was obtained. These bin times were then contoured in ArcView, Version 3.2 (ESRI 1999), using the default values set for proximity assignment. Each of these contours represented the percentage of time that an individual fish resided within that area. For example, the $95 \%$ contour represented the area within which a fish spent $95 \%$ of its time. We follow Anderson (1982) in using this value to define an animal's home range. Within the home range, discrete core areas were defined as areas of
$>50 \%$ usage that were $>40 \mathrm{~m}$ in diameter. For fish that received pingers by feeding, the entire period of tracking was represented in 1 home-range estimate. For fish that received pingers surgically, a longer time-series of data was available. To monitor the consistency of movements, 4 separate home-range estimates, representing 4 different time periods, were calculated for each of the tagged fish. These were chosen in order to represent the time between new moons, as a precaution to eliminate any unknown lunar effect on snapper behaviour, and were: (1) 6 February to 6 March; (2) 6 March to 5 April; (3) 5 April to 4 May; (4) 4 May to 3 June.

\section{RESULTS}

\section{Long-term residency}

All 5 surgically tagged snapper remained attached to areas within the detection range of the tracking system (ca. $1000 \mathrm{~m}$ ), from the time of release (January or February 2000) until the cessation of this study (June 2000). After continuous tracking ceased, 4 of these snapper were relocated $50 \mathrm{wk}$ after they were originally released, using a diver-operated receiver. All relocations were within the same home ranges previously occupied by the fish. By mid-February 2001 no fish could be detected, which was probably due to the expiration of pinger batteries. By this time the pinger batteries were $>200$ d past their previously estimated capacity.

\section{Home range and utilisation distribution}

$$
\text { Surgically tagged fish }
$$

The home-range area of the 5 surgically tagged snapper varied between 13960 and $230000 \mathrm{~m}^{2}$, whereas the area contained within the $50 \%$ contour varied from 1700 to $14800 \mathrm{~m}^{2}$ (Table 2, Figs. 2 to 7 ). The largest average home range of an individual was 3.5 times greater than the smallest (i.e. $99500 \mathrm{~m}^{2}$ for Fish S1 vs $28400 \mathrm{~m}^{2}$ for Fish S5). Perhaps the best illustration of this individual variation was the contrasting movements of Fish S2 and S4. For the second monitoring period, Fish S2 spent $30.4 \%$ of its time within one $20 \times 20 \mathrm{~m}$ bin, while for the third monitoring period the highest per-bin usage for Fish S4 was only $1.3 \%$. There was no evidence of territoriality, as home ranges and core areas overlapped considerably (Figs. 2 to 7 ).

The size of individual home ranges changed with time, but not consistently. Between the first and last monitoring periods 3 fish increased and 2 fish decreased their home-range areas. For example, Fish S2 (Fig. 3) increased its home-range area by $24 \%$ be- 
Table 2. Pagrus auratus. Home-range summary statistics for surgically tagged snapper. Each monitoring period represents a full lunar cycle

\begin{tabular}{|c|c|c|c|c|c|c|c|}
\hline Fish no. & $\begin{array}{l}\text { Monitoring } \\
\text { period }\end{array}$ & $\begin{array}{l}\text { Area within } \\
95 \% \text { contour } \\
\left(\mathrm{m}^{2}\right)\end{array}$ & $\begin{array}{l}\text { Area within } \\
50 \% \text { contour } \\
\left(\mathrm{m}^{2}\right)\end{array}$ & $\begin{array}{c}\text { Most intensive } \\
\text { usage per } 20 \mathrm{~m} \text { bin } \\
(\%)\end{array}$ & $\begin{array}{l}50: 95 \% \\
\text { ratio } \\
(\%)\end{array}$ & $\begin{array}{c}\text { No. of core } \\
\text { areas }\end{array}$ & $\begin{array}{l}\text { Movement of } \\
\text { each core } \\
\text { area }(\mathrm{m})\end{array}$ \\
\hline \multirow[t]{5}{*}{$\mathbf{S 1}$} & 1 & 80600 & 10300 & 6.5 & 12.78 & 1 & \\
\hline & 2 & 139600 & 9900 & 6.4 & 7.09 & 1 & 32.2 \\
\hline & 3 & 90700 & 14800 & 3.8 & 16.32 & 1 & 9.8 \\
\hline & 4 & 87100 & 13600 & 5.4 & 15.61 & 3 & 9.4 \\
\hline & Mean \pm SE & $99500 \pm 13500$ & $12200 \pm 1200$ & $5.5 \pm 0.63$ & $12.95 \pm 2.10$ & $1.5 \pm 0.5$ & $17.1 \pm 6.52$ \\
\hline \multirow[t]{5}{*}{$\mathbf{S} 2$} & 1 & 43800 & 2100 & 21.2 & 4.79 & 1 & \\
\hline & 2 & 29400 & 1200 & 30.4 & 4.08 & 1 & 5 \\
\hline & 3 & 43600 & 2400 & 14.9 & 5.50 & 2 & 3 \\
\hline & 4 & 35400 & 1800 & 23.7 & 5.08 & 1 & 3.6 \\
\hline & Mean \pm SE & $38000 \pm 3500$ & $1900 \pm 300$ & $22.6 \pm 3.2$ & $4.87 \pm 0.30$ & $1.3 \pm 0.25$ & $3.9 \pm 0.51$ \\
\hline \multirow[t]{5}{*}{ S3 } & 1 & 54400 & 7700 & 9 & 14.15 & 2 & \\
\hline & 2 & 46200 & 6000 & 11.9 & 12.99 & 2 & 1.0 and 37.0 \\
\hline & 3 & 52400 & 5800 & 12.3 & 11.07 & 2 & 8.1 and 17.5 \\
\hline & 4 & 69600 & 7700 & 12 & 11.06 & 2 & 12.4 and 34.0 \\
\hline & Mean \pm SE & $55600 \pm 5000$ & $6800 \pm 500$ & $11.3 \pm 0.77$ & $12.32 \pm 0.76$ & 2 & $\begin{array}{c}7.2 \pm 2.88 \\
\text { and } 29.5 \pm 6.49\end{array}$ \\
\hline \multirow[t]{5}{*}{ S4 } & 1 & 46700 & 1700 & 5.4 & 3.60 & 1 & \\
\hline & 2 & 61200 & 7200 & 1.4 & 11.76 & 4 & 219.1 \\
\hline & 3 & 56200 & 5400 & 1.3 & 9.61 & 2 & 10.4 and 57.8 \\
\hline & 4 & 60300 & 5300 & 1.6 & 8.79 & 2 & 10.0 and 94.6 \\
\hline & Mean \pm SE & $56100 \pm 3300$ & $4900 \pm 1200$ & $2.4 \pm 1$ & $8.45 \pm 1.72$ & $2.3 \pm 0.63$ & $\begin{array}{c}79.8 \pm 69.6 \\
\text { and } 76.2 \pm 18.4\end{array}$ \\
\hline \multirow[t]{5}{*}{ S5 } & 1 & 35800 & 1900 & 4.1 & 5.31 & 2 & \\
\hline & 2 & 23000 & 2500 & 3.9 & 10.87 & 2 & 5.4 and 5.4 \\
\hline & 3 & 24800 & 2300 & 4.2 & 9.27 & 1 & 16.8 \\
\hline & 4 & 30000 & 2700 & 3.7 & 9.00 & 1 & 9.9 \\
\hline & Mean \pm SE & $28400 \pm 2900$ & $2300 \pm 200$ & $4.0 \pm 0.11$ & $8.61 \pm 1.17$ & $1.5 \pm 0.29$ & $10.7 \pm 2.44$ \\
\hline $\begin{array}{l}\text { Overall } \\
\text { mean } \pm \mathrm{SE}\end{array}$ & & $55500 \pm 6200$ & $5600 \pm 900$ & $9.2 \pm 1.80$ & $9.44 \pm 0.87$ & $1.7 \pm 0.18$ & $32.1 \pm 10.71$ \\
\hline
\end{tabular}

tween February and June. The size of the $50 \%$ contour did not always remain in constant proportion to the size of the overall home range. However, the $50 \%$ contour was always between 3.6 and $16.3 \%$ of the size of the overall home range. Individual variation of this ratio provided a good indication of the level of residency within the home range. In general, as home-range size increased, so did the area contained within the 50\% contour. For example, Fish S1 had both the largest average value for its home range and also the largest average area within the $50 \%$ contour $\left(12200 \mathrm{~m}^{2}\right.$ ) (Table 2 ), producing an average $50: 95 \%$ ratio of $12.95 \%$. This was the highest 50:95\% ratio observed here, indicating that this fish used the space within its home range more evenly than the other fish tagged in this study.

All 5 fish had more than 1 core area for at least 1 of the monitoring periods. For all fish, except Fish S4, the core areas were relatively stable in location, moving no more than $37 \mathrm{~m}$ between monitoring periods. By visually following the shape of an individual fish's home range over the 4 monitoring periods, it was possible to confirm that the shape of the home range and the location of the most intensively used areas remained relatively constant (Figs. 2 to 7 ). Core areas appeared (Fig. 2d) and disappeared (Fig. 3c,d), but home ranges generally appeared to contain at least 1 consistent core area. This 'main' core area was not necessarily at the centre of the home range.

The exception, Fish S4, shifted its home range between 6 March and 5 April by $220 \mathrm{~m}$ (Fig. 5a,b). During the second monitoring period (Fig. 5b), a series of core areas from west to east was exhibited. This presumably represented the different areas this fish resided in as it was shifting home range over the period of $1 \mathrm{mo}$. In the last 2 monitoring periods the eastern-most of these core areas became stable. The completeness of this homerange shift is further emphasised by the fact that after April the fish did not return to its previous core area.

Fish tagged by feeding

The home range size of snapper that were fed tags varied between 3900 and $50329 \mathrm{~m}^{2}$, and the area 

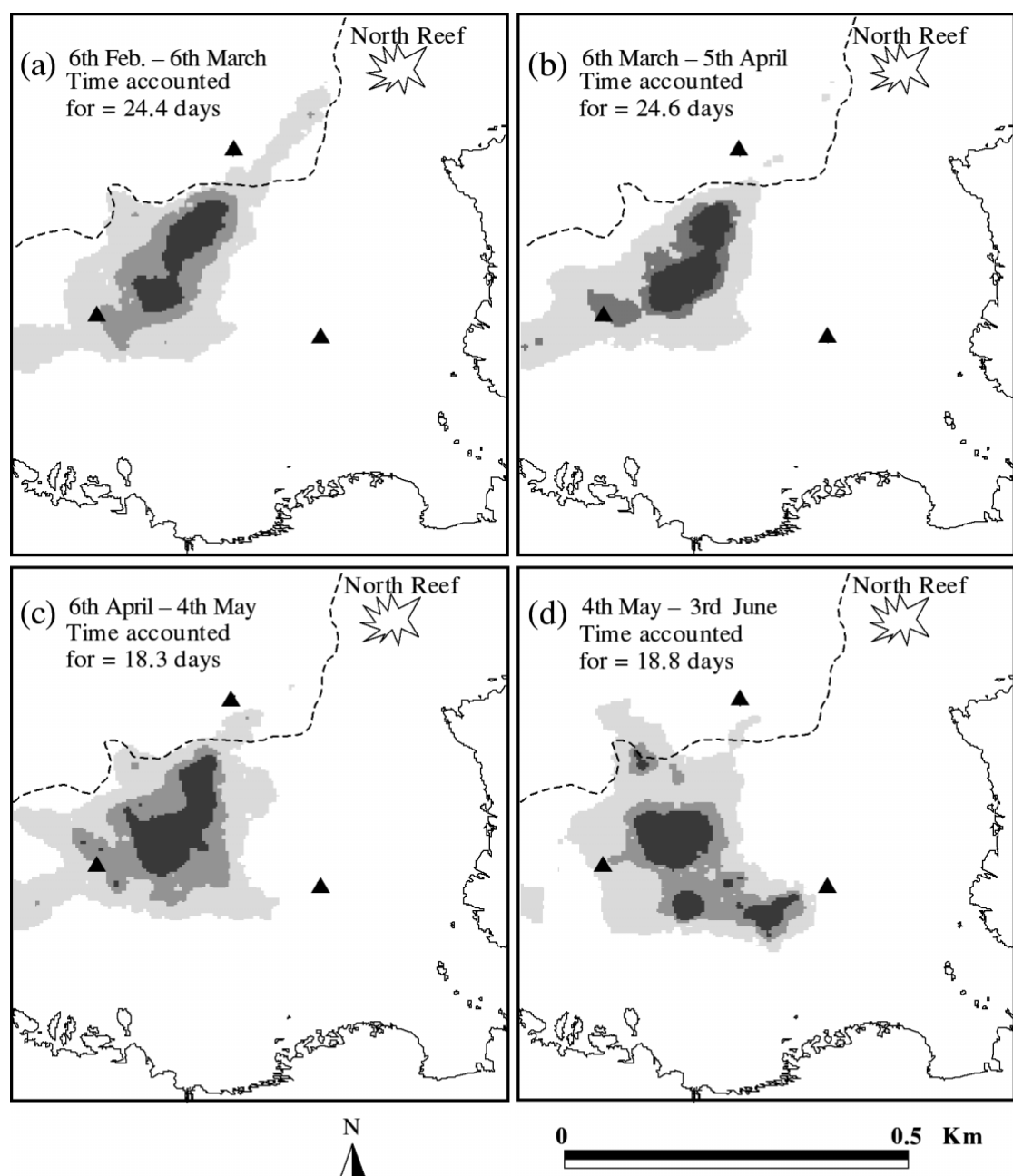

\ Sono-buoys

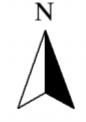

Reef-sand interface

Contours containing percentage of usage $95 \%$ $75 \%$

$\mathbf{5 0} \%$

Fig. 2. Pagrus auratus. Home range and utilisation distributions of Fish S1 (400 mm fork length) for 4 lunar cycles between February and June 2000 within the $50 \%$ contour varied from 122 to $2901 \mathrm{~m}^{2}$ (Table 3, Fig. 7). The highest per-bin usage intensity ranged from 12.2 to $43.6 \%$, while the number of core areas was either 1 or 2 .

The home-range sizes and areas of $50 \%$ usage for these fish were similar, but generally smaller than those of the snapper that received surgically inserted tags. Accordingly, the highest per-bin usage values were generally greater than those of the surgically tagged snapper. This was due to the short monitoring time, 0.1 to $2.3 \mathrm{~d}$, relative to surgically tagged (minimum of $6.7 \mathrm{~d}$ ) snapper. To account for these differences, 11 portions of data were selected, each with a length equal to one of the monitoring periods of fish tagged by feeding. Home ranges were then estimated for these randomly selected portions of data. Paired comparisons of these randomly selected home ranges and the home ranges of fish tagged by feeding revealed no significant difference (Wilcoxon signed rank sum, $p>0.05)$. This indicated that both tagging methods produced similar range estimates, but also that shorter monitoring periods underestimated the true extent of a fish's movements. The relationship between home-range size and the duration of the calculation period

Table 3. Pagrus auratus. Home-range summary statistics of snapper that received tags by feeding

\begin{tabular}{|c|c|c|c|c|c|}
\hline Fish no. & $\begin{array}{l}\text { Area within } \\
95 \% \text { contour } \\
\left(\mathrm{m}^{2}\right)\end{array}$ & $\begin{array}{l}\text { Area within } \\
50 \% \text { contour } \\
\left(\mathrm{m}^{2}\right)\end{array}$ & $\begin{array}{c}\text { Most intensive } \\
\text { usage per } 20 \mathrm{~m} \text { bin } \\
(\%)\end{array}$ & $\begin{array}{c}50: 95 \% \\
\text { ratio } \\
(\%)\end{array}$ & $\begin{array}{l}\text { No. of } \\
\text { activity } \\
\text { centres }\end{array}$ \\
\hline F1 & 26235 & 1965 & 16.1 & 7.49 & 1 \\
\hline F2 & 18290 & 433 & 17.6 & 2.37 & 1 \\
\hline F3 & 17097 & 1355 & 12.2 & 7.93 & 2 \\
\hline $\mathrm{F} 4$ & 12297 & 813 & 13.3 & 6.61 & 1 \\
\hline F5 & 10345 & 1138 & 31.2 & 11.00 & 1 \\
\hline F6 & 23998 & 1342 & 14.6 & 5.59 & 2 \\
\hline F7 & 50329 & 2901 & 12.7 & 5.76 & 2 \\
\hline F8 & 3877 & 325 & 40.7 & 8.38 & 1 \\
\hline F9 & 13666 & 1084 & 17.0 & 7.93 & 1 \\
\hline F10 & 11226 & 976 & 31.2 & 8.69 & 1 \\
\hline F11 & 11117 & 122 & 43.6 & 1.10 & 1 \\
\hline Average \pm SE & $18648 \pm 3757$ & $1114 \pm 238$ & $23.9 \pm 3.53$ & $6.62 \pm 0.86$ & $1.3 \pm 0.14$ \\
\hline
\end{tabular}


was further investigated. Home ranges were estimated for randomly selected portions of data with lengths between 1 and $30 \mathrm{~d}$. While there was large variance, most probably due to differences between individual fish, it appeared that home range size stabilised when $\geq 7 \mathrm{~d}$ of monitoring were used in the calculation (Fig. 8).

\section{Response to human activity}

While using the diver-operated receiver, numerous attempts were made to visually re-sight each of the surgically tagged snapper. On every occasion, the tagged fish would allow divers to approach to a close distance, as indicated by the signal strength on the receiver, but would not come within the diver's visual range, regardless of water clarity. These surgically tagged snapper maintained this behaviour for the duration of the study (>5 mo). In marked contrast, snapper that received tags via feeding were not as cautious, and the pinger signal led to visual relocation on every attempt.

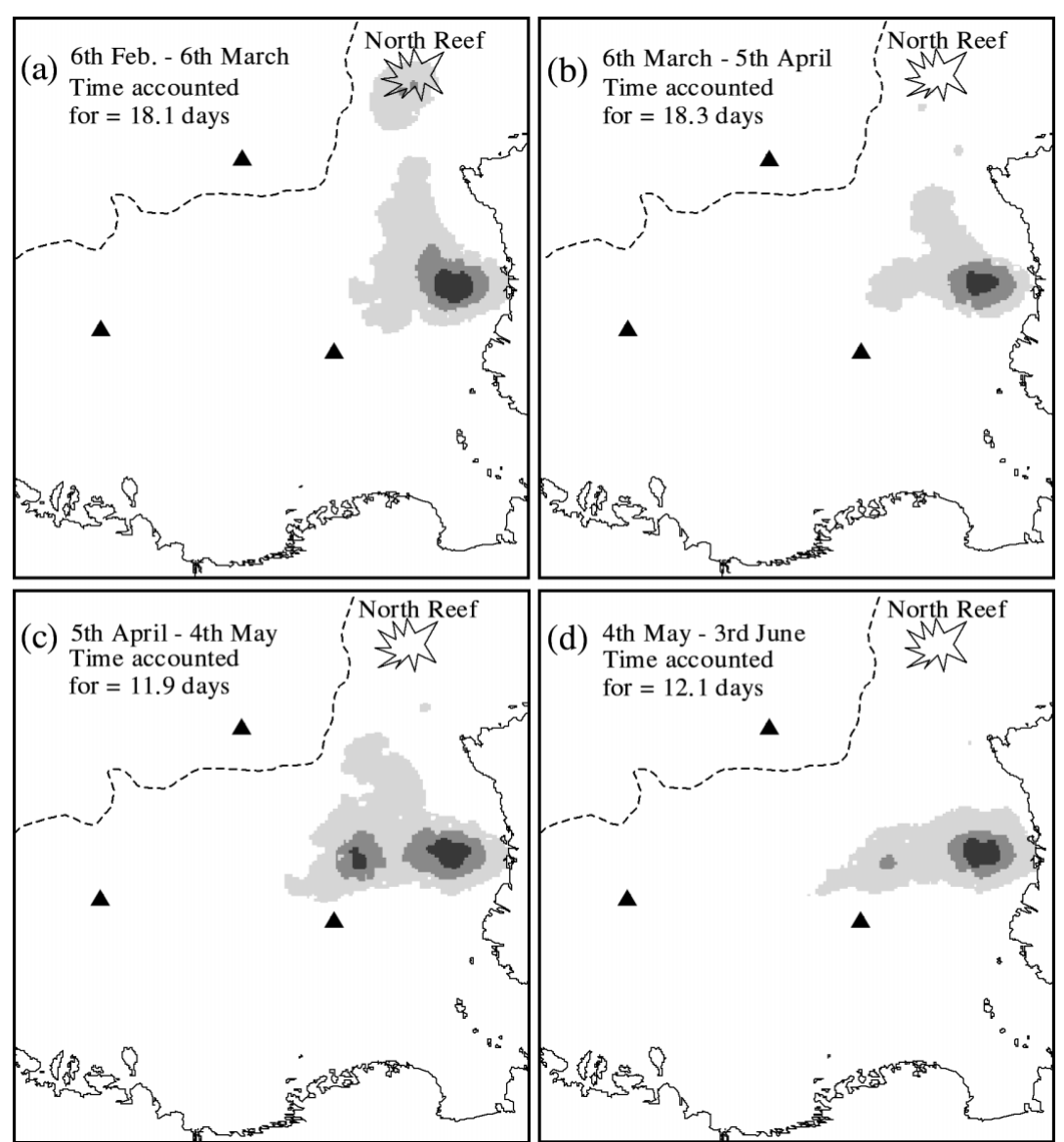

Fig. 3. Pagrus auratus. Home range and utilisation distributions of Fish S2 (415 mm fork length) for 4 lunar cycles between February and June 2000. Symbols and shading as in Fig. 2

\section{Unaccountable time}

The amount of time an individual snapper was unaccountable during a lunar tracking period varied from as little as 4.4 to as much as $22.8 \mathrm{~d}$ (Figs. 2 to 7 ). There are 4 possible reasons why the RAPT system could not account for snapper positions: (1) tagged snapper were moving to areas outside the detection range of the system; (2) tagged snapper were moving to areas where the system was obstructed; (3) extreme sea conditions reduced the amount of time that fish could be detected; and (4) the system was shut down intermittently. The first of these possibilities only appeared to make a major contribution to the home range estimate of Fish S1 (Fig. 2). Here, part of the home range was excluded from analysis by discarding locations outside its western border. For Fish S2 and S4 (Figs. 3 \& 5, respectively), a combination of explanations (2) and (3) is most likely. The habitats these fish occupied were shallow and complex. Therefore, when storm conditions occurred, the fish were most likely to have their signals obstructed, as their habitats are areas most prone to turbulence. Indeed, the frequency of storm conditions (wave surge $>2 \mathrm{~m}$ ) was greatest in the last 2 monitoring periods (Table 4), which could explain why these fish had the lowest percentage of time accounted for during these periods. The 3rd and 4 th possibilities are likely to explain the majority of the remaining unaccounted time. When storm conditions occurred, the tracking system often produced spurious buoy and fish positions (hundreds of metres from where they should have been). Data files containing such positions were deleted to avoid incorporating errors into home-range estimates. Storm conditions also made it difficult to replace the sono-buoy batteries, resulting in the system being frequently shut down. Finally, during the last 2 monitoring periods, the system was used to construct a habitat map (D. M. Parsons, N. T. Shears, R. C. Babcock unpubl.). This resulted in extended lengths of time when the system was not searching for fish. When these periods of missing data were totalled (Table 4), a large proportion of these data could be accounted for, especially in the last 2 monitoring periods when bad 

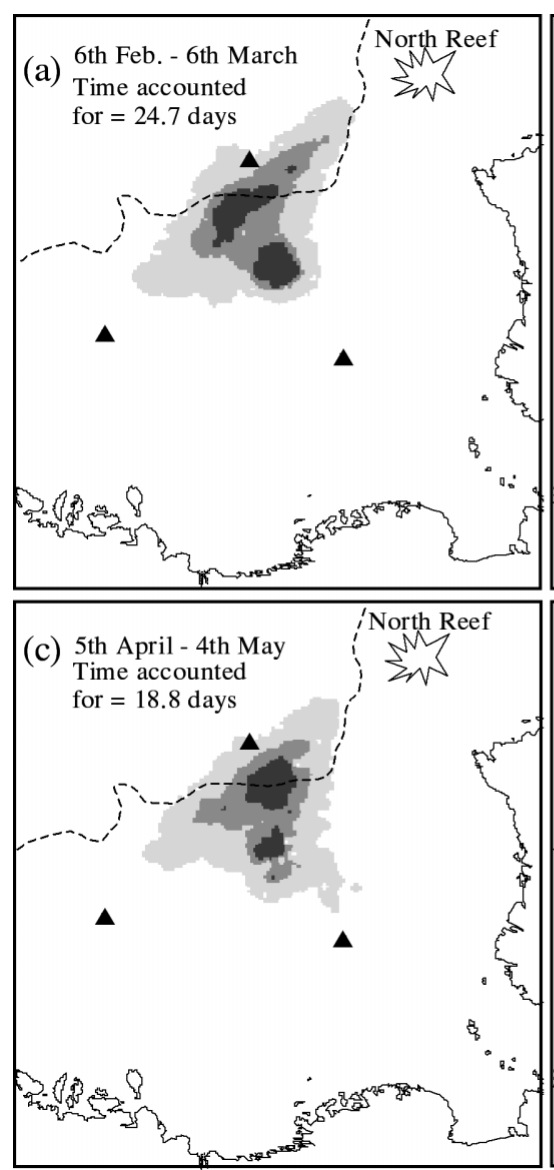

(b) 6th March - 5th April

'North Reef

Time accounted for $=25.1$ days
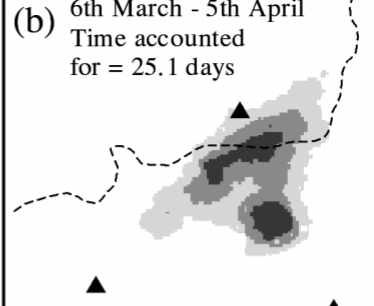
in 
(5 mo). This decision appeared to be reasonable due to the individual consistency of home-range size ( $<24 \%$ change over $4 \mathrm{mo}$ ), and stasis of home-range location throughout the entire 5 mo tracking period ( $<37 \mathrm{~m}$ movement of core areas for all fish except S4). Snapper that received tags by feeding were not included in this estimate due to differences in the length of the monitoring period. Because home range is a function of time as well as space, the period over which home ranges are estimated must be taken into consideration in order to make estimates comparable (White \& Garrott 1990). Further investigation of this issue revealed that the area used by an individual snapper did not appear to increase when $\geq 7 \mathrm{~d}$ of monitoring were incorporated in the estimate. Therefore, home-range estimates based on periods of monitoring up to $2.3 \mathrm{~d}$ are not directly comparable to home ranges estimated over a month, and we recommend that at least $7 \mathrm{~d}$ of monitoring be used in future calculations of snapper home range. For this reason, the monitoring of snapper tagged by feeding served 2 important purposes: (1) It demonstrated that the range of movements that these fish exhibited was not dissimilar to the movements of the surgically tagged fish. This lends confidence to the idea that the surgical procedure did not drastically alter the space-use characteristics of snapper; and (2) the 11 snapper fed acoustic tags also increased the sample size of fish that expressed smallscale residency.

\section{Utilisation distribution}

The use of space within the home ranges estimated here was not uniform. Each snapper spent $50 \%$ of its time within an area that was only 3.6 to $16.3 \%$ of the total home-range size. In general, the area within which snapper spent $\geq 50 \%$ of their time ranged between 1700 and $14800 \mathrm{~m}^{2}$, or 55 and $200 \mathrm{~m}$ in diameter. This implied that while they were observed ranging over an area of up to $620 \mathrm{~m}$ diameter, most of the time they were within an area of only $200 \mathrm{~m}$ diameter. The most extreme example was Fish S4 (Fig. 5).
During the first monitoring period, this fish spent $50 \%$ of its time in an area of only $1700 \mathrm{~m}^{2}$, or $55 \mathrm{~m}$ diameter.

All surgically tagged fish had more than 1 core area in at least 1 of the monitoring periods, and these core areas were not always located at the centre of the home range. This is logical, as some areas could provide better shelter or food than others. It remains unknown whether these core areas are located where a fish resides when it is inactive (e.g. Løkkeborg et al. 2000) or whether a disproportionate amount of foraging and/or social interaction are occurring at these locations. Regardless of which resources are being utilised, they are unlikely to be distributed uniformly. Therefore, it was not unexpected that fish home ranges were irregular.

With respect to other marine fish species, only 5 studies have investigated the use of space within the home range. Four of these studies used manual tracking (Holland et al. 1993, 1996, Meyer et al. 2000, Eristhee \& Oxenford 2001), while one used an automated system (Cote et al. 1998). The short duration of these studies $(<62 \mathrm{~d})$, the intermittent periods of track- 


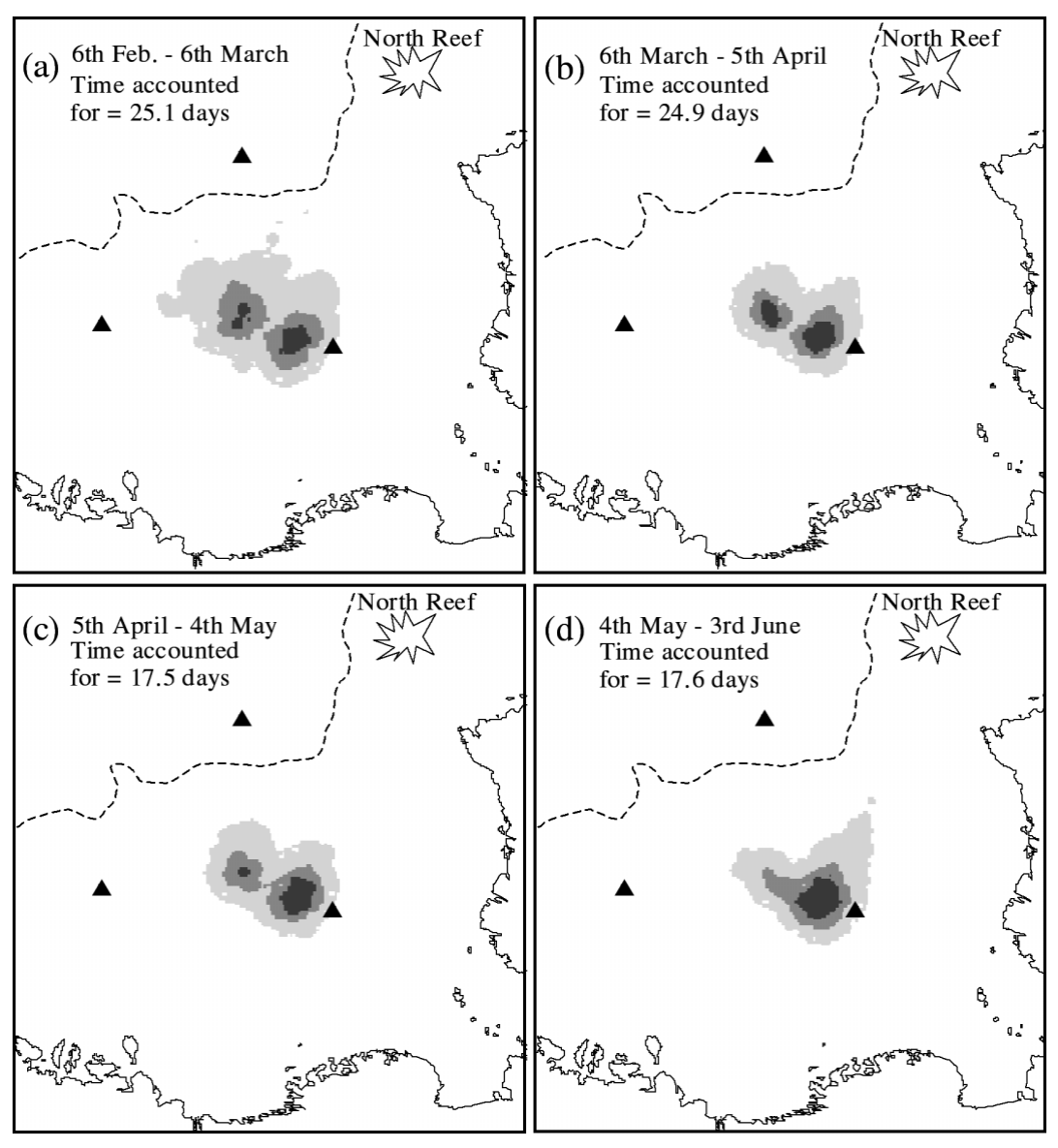

Fig. 6. Pagrus auratus. Home range and utilisation distributions of Fish S5 (515 mm fork length) for 4 lunar cycles between February and June 2000. Symbols and shading as in Fig. 2 sonal patterns that snapper exhibit while spawning (Scott et al. 1993). While it is not possible to discern the reason for these movements from this analysis, it is possible that: (1) North Reef was the site of a localised spawning aggregation within the reserve; and (2) structures such as North Reef could be used as a geographic marker for historic spawning aggregations.

\section{Home-range stability}

Four of the surgically tagged fish maintained home ranges with a consistent shape and location ( $<37$ m movement between monitoring periods). Such stability was not expressed by Fish S4. Between the second and third monitoring periods, this fish increased the number of core areas it was using from 1 to 4 (Fig. 4b). These core areas led from west to east across Goat Island Bay. Illustration of this movement using $5 \mathrm{~d}$ portions of time (not presented) revealed that core-area shifting was a gradual process. New core areas were established by gradually increasing the use of an alternate area, while the use of the original core area was maintained. Similarly, core areas were abandoned by gradually decreasing the use of them. This fish maintained 3 core areas at one time. By the 4 th monitoring period it had established, and then rejected, or was evicted from, 2 core areas before settling in the eastern-most core area. This suggested that some time between 6 March and 5 April, this fish relocated its home range by ca. $220 \mathrm{~m}$. During the last monitoring period, the core area of the first monitoring period was not revisited. Therefore any resources available within the original core area were obtained from its new home range or not required at all. Kramer \& Chapman (1999) speculated that relocations were most likely to occur after several sampling trips from the established home range. This probably was the case here.

Relocation events could be initiated by seasonal change of an environmental variable (e.g. wave exposure or the abundance of prey). At this time of year a proportion of the snapper population follow a seasonal off-reef migration (Crossland 1976, Willis et al. 2003), which might also have some influence on 
within-reef movements. Other factors that may effect home range shifts could include the interaction with other snapper. In the current study considerable home-range overlap was observed. In addition, the high density of snapper within Goat Island Bay (Willis et al. 2003) precludes the possibility that individual home ranges of this size could be occupied exclusively. This suggests 2 things: (1) the carrying capacity of a reserve, or any other area, cannot be calculated by dividing area by the average size of a snapper home range; and (2) movements between different areas are not restricted by the possibility of entering another snapper's home range.

While Willis et al. (2001) demonstrated that snapper were resident within the CROP Reserve, results presented in the current study indicate that these fish did not leave the reserve between location fixes. In short, it was possible to quantify the size and permanency of snapper home ranges. Other studies of snapper movement have also suggested that snapper were resident, but at much larger scales. With respect to
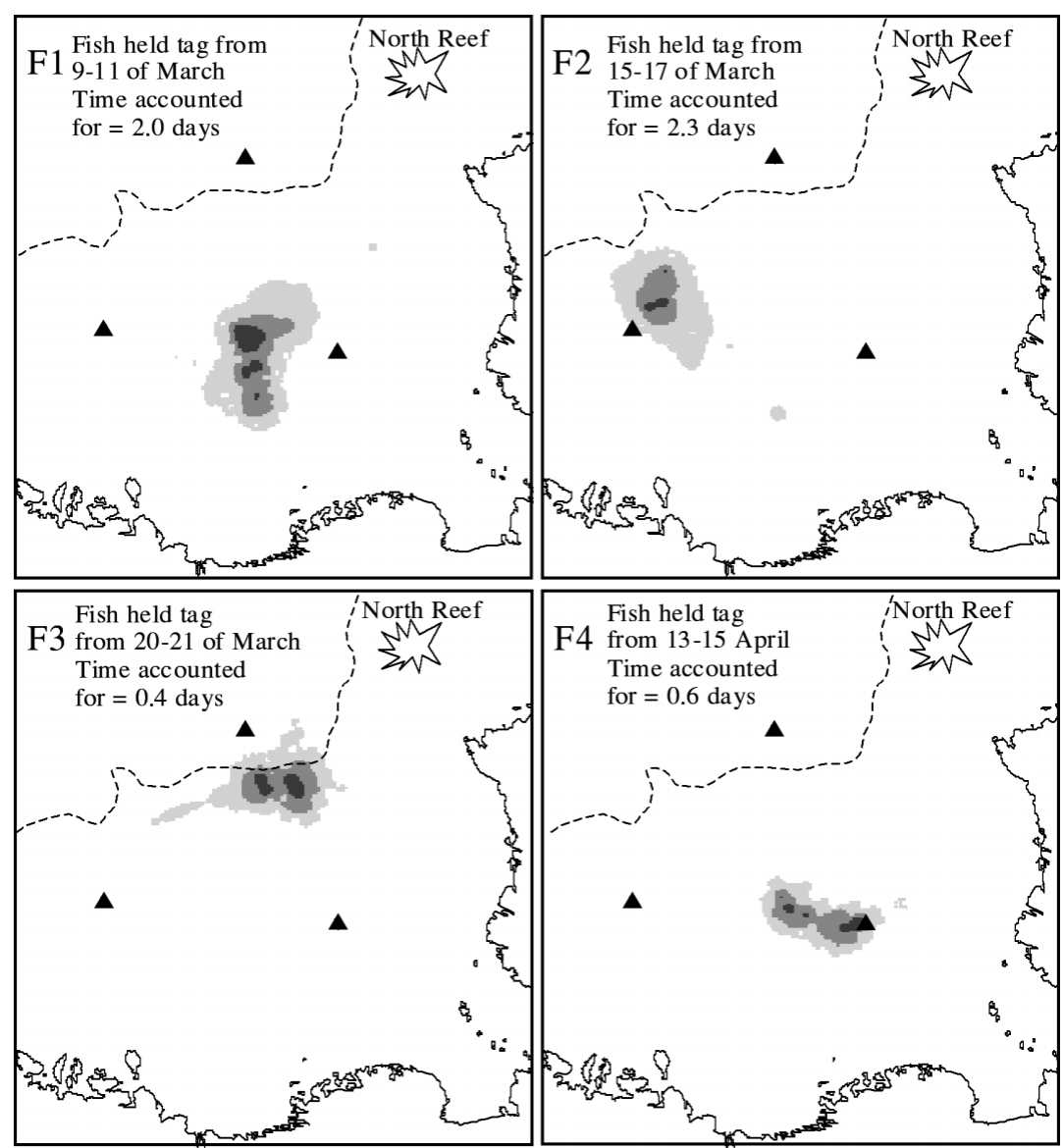

Fish held tag F4 from 13-15 April Time accounted for $=0.6$ days

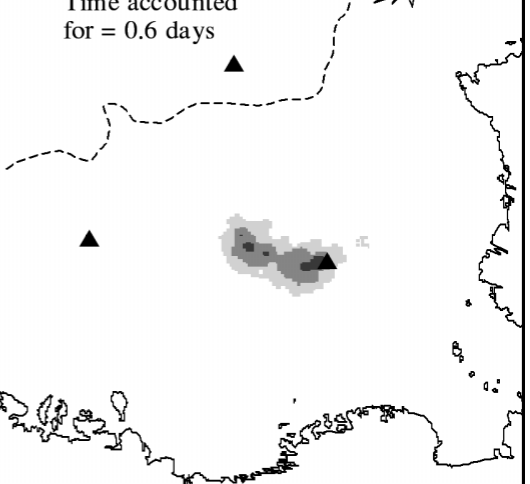

Fig. 7. Pagrus auratus. Home range and utilisation distributions of 4 of the fish that received acoustic tags. Fork lengths: $\mathrm{F} 1=325 \mathrm{~mm}, \mathrm{~F} 2=400 \mathrm{~mm}, \mathrm{~F} 3=450 \mathrm{~mm}$, $\mathrm{F} 4=400 \mathrm{~mm}$. Symbols and shading as in Fig. 2 the scales investigated in this study, fish movement over scales of kilometres, as described by Paul (1967) and Crossland (1982), is referred to as mobile, whereas movement over hundreds of meters, as described here, is termed resident. Nevertheless, from the conclusions of these previous studies, and those presented here, it would appear that snapper are capable of exhibiting both vagile and residential behaviours. A similar pattern has been observed in the movement patterns of galjoen Coracinus capensis (Attwood \& Bennett 1994). While most of the galjoen tagged were recaptured within $5 \mathrm{~km}$ of the release site, $17.8 \%$ were caught $>25 \mathrm{~km}$ away, the greatest distance to recapture being $1040 \mathrm{~km}$.

Within the CROP Reserve, indirect evidence suggests that some snapper are wider dispersing than those tagged in this study. Willis et al. (2003) monitored the density of snapper throughout 3 NE New Zealand marine reserves and their adjacent fished areas. Con-

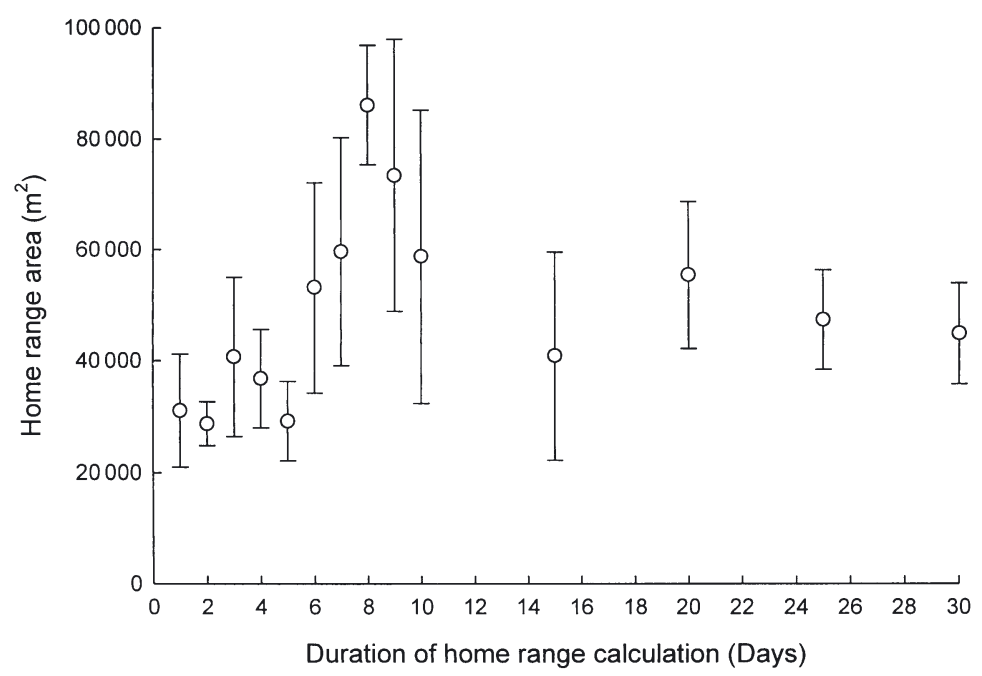

Fig. 8. Pagrus auratus. Relationship between home-range size and length of time used in the calculation. Values represent means \pm SE $(n=3)$ 
sistent seasonal fluctuations of snapper abundance, both inside and outside reserves, suggested that part of the inshore snapper population was not resident and left coastal areas sometime between April and October. The fact that similar fluctuations existed outside of reserves indicates that this pattern is probably not restricted to marine reserves.

If fisheries select for different traits through increased mortality (e.g. size: Hilborn \& Walters 1992; sex ratio: McGovern et al. 1998; growth rate: Conover \& Munch 2002; genetic heterozygosity: Hauser et al. 2002), then marine reserves may change this selection regime and exert their own selective pressure through decreased mortality. The observation that all snapper tagged in this study resided in areas 2 orders of magnitude smaller than previously documented (Paul 1967, Crossland 1982) may be due to the behavioural selections caused by such a reserve. The explanation is as follows: Within the snapper population a continuum of mobility behaviour exists. Within reserves, the fish with the highest tendency to exhibit residential behaviour are favoured. This is due to the small size of established reserves $\left(<9 \mathrm{~km}^{2}\right)$ and the heavy fishing pressure on their boundaries (T. J. Willis pers. obs.). Any snapper of higher mobility would therefore spend at least some time outside of the reserve, increasing the chance of capture. If all snapper were uniformly as mobile as described by Paul (1967) and Crossland (1982), then it is likely that snapper abundances would not have responded as positively to protection within reserves of the current size (Willis et al. 2003). Those estimates reflect the average mobility of a population whose behavioural distribution may have been altered by exploitation, whereas the estimates presented in this study represent individual estimates from a population with behavioural traits that may have been affected by a lack of exploitation. This scenario illustrates 2 important points: (1) within a species, assumptions about homogeneous behaviour cannot always be made (Willis et al. 2001), and management decisions, rather than being based on such assumptions, are likely to have unexpected and possibly unfavourable consequences; and (2) a marine reserve's potential to replenish adjacent fisheries will be dependent on the reproductive and growth potential of the individuals it selects for.

Acknowledgements. We thank the Department of Conservation and the Vice Chancellors Committee of the University of Auckland for providing funding and financial assistance. A loan of equipment was gratefully received from G. Russ of James Cook University (VUR 96). We would also like to thank G. Allen for developing the home range model, D. Webber for assistance with position calculation, N. Tolimieri and 3 reviewers for comments on the manuscript, and D. Feary and numerous other voluntary field assistants.

\section{LITERATURE CITED}

Allison GW, Lubchenco J, Carr MH (1998) Marine reserves are necessary but not sufficient for marine conservation. Ecol Appl 8(Suppl):79-92

Anderson DJ (1982) The home range: a new nonparametric estimation technique. Ecology 63:103-112

Annala JH, Sullivan KJ, O'Brien CJ (1999) Report from the Fishery Assesment Plenary, April 1999: stock assesments and yield estimates (unpublished report held in NIWA library, Wellington, NZ)

Attwood CG, Bennett BA (1994) Variation in dispersal of galjoen (Coracinus capensis) (Teleostei: Coracinidae) from a marine reserve. Can J Fish Aquat Sci 51:1247-1257

Babcock RC, Kelly S, Shears NT, Walker JW, Willis TJ (1999) Changes in community structure in temperate marine reserves. Mar Ecol Prog Ser 189:125-134

Berquist RM (1994) Patterns of activity and movement in New Zealand snapper, Pagrus auratus. MSc thesis, University of Auckland

Blaxter JHS, Dickson W (1959) Observations of swimming speeds of fish. J Cons Int Explor Mer 24:472-479

Conover DO, Munch SB (2002) Sustaining fisheries yields over evolutionary time scales. Science 297:94-96

Cote D, Scruton DA, Niezgoda GH, McKinley RS, Rowsell DF, Lindstrom RT, Ollerhead LMN, Whitt CJ (1998) A coded acoustic telemetry system for high precision monitoring of fish location and movement - application to the study of nearshore nursery habitat of juvenile Atlantic cod (Gadus morhua). Mar Technol Soc J 32:54-62

Crossland J (1976) Snapper tagging in North-East New Zealand, 1974: analysis of methods, return rates, and movements. NZ J Mar Freshw Res 10:675-686

Crossland J (1982) Movements of tagged snapper in the Hauraki Gulf. NZ Fish Res Div Occasional Publ No 35, MAF, Wellington

DeMartini EE (1993) Modelling the potential of fishery reserves for managing Pacific coral reef fishes. Fish Bull 91:414-427

Eaton JW, Rawlings JB (1995) OCTAVE-A high level interactive language for numerical computations. Cache News 40:11-18

Eristhree N, Oxenford HA (2001) Home range size and use of Bermuda chub Kyphosus sectatrix (L.) in two marine reserves in the Soufriere Marine Management Area, St Lucia, West Indies. J Fish Biol 59:129-151

ESRI (Environmental Systems Research Institute) (1999) Getting to know ArcView GIS: the geographic information system (GIS) for everyone. ESRI, Redlands, CA. PrenticeHall, Upper Saddle River, NJ

Gilbert DJ, McKenzie JR (1999) Sources of bias in biomass estimates from tagging programmes in the SNA 1 snapper (Pagrus auratus) stock. NZ Fish Assess Res Doc 99/16, $\mathrm{MoF}$, Wellington, NZ

Hauser L, Adcock GJ, Smith PJ, Ramirez JHB, Carvalho GR (2002) Loss of microsatellite diversity and low effective population size in an overexploited population of New Zealand snapper (Pagrus auratus). Proc Natl Acad Sci USA 99:11742-11747

Hilborn R, Walters CJ (1992) Quantitative fisheries stock assessment: choice, dynamics and uncertainty. Chapman \& Hall, New York

Holland KN, Peterson JD, Lowe CG, Wetherbee BM (1993) Movements, distribution and growth rates of the white goatfish Mulloides flavolineatus in a fisheries conservation zone. Bull Mar Sci 52:982-992

Holland KN, Lowe CG, Wetherbee M (1996) Movements and dispersal patterns of blue trevally (Caranx melampygus) 
in a fisheries conservation zone. Fish Res 25:279-292

Kramer DL, Chapman MR (1999) Implications of fish home range size and relocation for marine reserve function. Environ Biol Fish 55:65-79

Løkkeborg S, Skajaa K, Ferno A (2000) Food-search strategy in ling (Molva molva L.): crepuscular activity and use of space. J Exp Mar Biol Ecol 247:195-208

MathWorks (1998) MATLAB: the language of technical computing: computation, visualization, programming. Natick, MA

McGovern JC, Wyanski DM, Pashuk O, Manooch III CS, Sederberry GR (1998) Changes in the sex ratio and size at maturity of gag, Mycteroperca microlepis, from the Atlantic coast of the southeastern United States during 1976-1995. Fish Bull 96:797-807

Meyer CG, Holland KN, Wetherbee BM, Lowe CG (2000) Movement patterns, habitat utilization, home range size and site fidelity of whitesaddle goatfish, Parupeneus porphyreus, in a marine reserve. Environ Biol Fish 59: 235-242

Moran WA (1987) Tagging confirms separate stocks of snapper in Shark Bay region. Fins 20:3-8

Munday PL, Wilson SK (1997) Comparative efficacy of clove oil and other chemicals in anaesthetization of Pomacentrus amboinensis, a coral reef fish. J Fish Biol 51:931-938

O'Dor RK, Andrade Y, Webber DM, Sauer WHH, Roberts MJ, Smale MJ, Voegeli FM (1998) Applications and performance of radio-acoustic positioning and telemetry (RAPT) systems. Hydrobiologia 372:1-8

Paul LJ (1967) An evaluation of tagging experiments on the New Zealand snapper, Chrysophrys auratus (Forster), during the period 1952 to 1963. NZ J Mar Freshw Res 1: 455-463

Paul LJ (1976) A study on age, growth, and population structure of the snapper, Chrysophrys auratus (Forster), in the Hauraki Gulf, New Zealand. Fisheries Research Division. Fish Res Bull No. 13, MAF, Wellington, NZ

Editorial responsibility: Otto Kinne (Editor),

Oldendorf/Luhe, Germany
Roberts CM, Polunin NVC (1991) Are marine reserves effective in management of reef fisheries? Rev Fish Biol Fish 1:65-91

Schoener TM (1981) An empirically based estimate of home range. Theor Pop Biol 20:281-325

Scott SG, Zeldis JR, Pankhurst NW (1993) Evidence of daily spawning in natural populations of the New Zealand snapper Pagrus auratus (Sparidae). Environ Biol Fish 36: 149-156

Shears NT, Babcock RC (2002) Marine reserves demonstrate top-down control of community structure on temperate reefs. Oecologia 132:131-142

White GC, Garrot RA (1990) Analysis of wildlife radiotracking data. Academic Press, San Diego

Willis TJ, Babcock RC (1998) Retention and in situ detectability of visible implant fluorescent elastomer (VIFE) tags in Pagrus auratus (Sparidae). NZ J Mar Freshw Res 32: $247-254$

Willis TJ, Millar RB (2001) Modified hooks reduce incidental mortality of snapper (Pagrus auratus) in the New Zealand commercial longline fishery. ICES J Mar Sci 58:830-841

Willis TJ, Millar RB, Babcock RC (2000) Detection of spatial variability in relative density of fishes: comparison of visual census, angling, and baited underwater video. Mar Ecol Prog Ser 198:249-260

Willis TJ, Parsons DM, Babcock RC (2001) Evidence for longterm site fidelity of snapper (Pagrus auratus) within a marine reserve. NZ J Mar Freshw Res 35:581-590

Willis TJ, Millar RB, Babcock RC (2003) Protection of exploited fishes in temperate regions: high density and biomass of snapper Pagrus auratus (Sparidae) in northern New Zealand marine reserves. J Appl Ecol 40:214-227

Woodroffe R, Ginsberg JR (1998) Edge effects and the extinction of populations inside protected areas. Science 280: $2126-2128$

Zeller DC (1997) Home range and activity patterns of the coral trout Plectropomus leopardus (Serranidae). Mar Ecol Prog Ser 154:65-77

Submitted: January 29, 2003; Accepted: July 22, 2003

Proofs received from author(s): October 27, 2003 